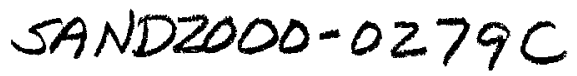

\title{
SEM/EDX SPECTRUM IMAging and Statistical Analysis of a METAL/CERAMIC BRAZE
}

PAUL G. KOTULA,' MICHAEL R. KEENAN' ${ }^{1}$ AND IAN M. ANDERSON ${ }^{2}$

${ }^{1}$ Sandia National Laboratories, PO Box 5800, Albuquerque, NM 87185-1405

${ }^{2}$ Oak Ridge National Laboratory, PO Box 2008, Oak Ridge, TN 37831-6376

\section{ABSTRACT}

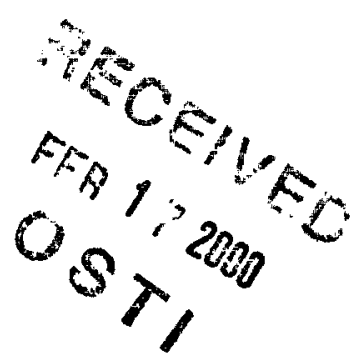

Energy dispersive x-ray (EDX) spectrum imaging has been performed in a scanning electron microscope (SEM) on a metal/ceramic braze to characterize the elemental distribution near the interface. Statistical methods were utilized to extract the relevant information (i.e., chemical phases and their distributions) from the spectrum image data set in a robust and unbiased way. The raw spectrum image was over 15 Mbytes ( 7500 spectra) while the statistical analysis resulted in five spectra and five images which describe the phases resolved above the noise level and their distribution in the microstructure.

\section{INTRODUCTION}

Spectrum imaging, where a complete $x$-ray spectrum is collected at every pixel in a scanned image, is a powerful new tool for materials characterization. Spectrum imaging differs from mapping, where only windows around pre-selected energy ranges are acquired, in that the entire spectrum is collected at each pixel, as the beam is rastered across the specimen. This procedure allows even unanticipated elements to be mapped after the data has been collected. However, mapping by itself is potentially fraught with errors [1]. Additionally, the spectrum image cannot readily be visualized in its entirety. For these reasons, a robust and unbiased method is needed to extract all of the relevant information from these large raw data files. Ideally, one would like a spectrum describing the elemental distribution, and a corresponding image describing the distribution, for each phase in the microstructure. In the present work we describe the application of multivariate statistical analysis (MSA) to a spectrum image of a metal/ceramic braze.

\section{EXPERIMENTAL}

The braze characterized in this work joins polycrystalline alumina to Kovar (primarily $\mathrm{Fe}, \mathrm{Ni}$ and $\mathrm{Co}$ ) with a copper-silver eutectic alloy containing some titanium (an 'active' metal). The specimen geometry consisted of a sandwich of two pieces of alumina, two braze layers and a Kovar filler layer in the middle. The entire assembly was heat-treated to bond the interfaces and then a polished cross-section was prepared. The interface between the alumina and the coppersilver alloy was characterized in this work. The analysis was performed in a Philips XL30-FEG SEM operated at $10 \mathrm{kV}$, equipped with an Oxford super-ATW detector and XP3 pulse processor. The specimen was normal to the electron beam and the take-off angle was $35^{\circ}$. EDX spectrum images were acquired with an EMiSPEC Vision integrated acquisition system. A spectrum image of $100 \times 75$ pixels with 1000 channels per spectrum (10 eV/channel) was acquired from the specimen with a sampling density of $200 \mathrm{~nm} /$ pixel and a dwell time of 1 live second per pixel, for a total acquisition time of $\sim 2$ hours. The binary data file was imported into MATLAB where the statistical analysis was performed on a $500 \mathrm{MHz}$ Pentium III with $512 \mathrm{Mbytes}$ of RAM. The entire calculation took six minutes. The linear and orthogonal MSA calculation scheme followed that of Trebbia and Bonnet [2-5]. The MSA seeks to identify the independently varying sources of information in the raw data set and then orders these based upon the amount of variance they describe. The first several resultant components of information then describe the chemical composition and distribution of the phases in the microstructure. The rest of the components describe the noise in the data, which for the case of EDS is due to Poisson statistics. 


\section{DISCLAIMER}

This report was prepared as an account of work sponsored by an agency of the United States Government. Neither the United States Government nor any agency thereof, nor any of their employees, make any warranty, express or implied, or assumes any legal liability or responsibility for the accuracy, completeness, or usefulness of any information, apparatus, product, or process disclosed, or represents that its use would not infringe privately owned rights. Reference herein to any specific commercial product, process, or service by trade name, trademark, manufacturer, or otherwise does not necessarily constitute or imply its endorsement, recommendation, or favoring by the United States Government or any agency thereof. The views and opinions of authors expressed herein do not necessarily state or reflect those of the United States Government or any agency thereof. 


\section{DISCLAIMER}

Portions of this document may be illegible in electronic image products. Images are produced from the best available original document. 


\section{RESULTS}

Figure 1 is a SEM secondary electron image of the analyzed area of the specimen. The microstructure consists of eutectic lamellae of $\mathrm{Cu}$ in $\mathrm{Ag}$ at the bottom of the image and polycrystalline alumina at the top of the image. The region of the spectrum image is delineated by a white rectangle. Figure 2 shows conventional maps for $\mathrm{Ti}, \mathrm{Fe}, \mathrm{Co}$, and $\mathrm{Ni}$, constructed after the spectrum image had been acquired. Figure 3 is the component spectrum and image describing contrast in the $\mathrm{Cu} / \mathrm{Ag}$ eutectic phases. Figures $4 \mathrm{a}$ and $\mathrm{b}$ are the component image and spectrum respectively from an interface intermetallic phase and Figures $4 \mathrm{c}$ and $\mathrm{d}$ are from Ti segregated to the metal ceramic interface. Figure 5 is the sum of $25 \mathrm{raw}$ spectra from the metal/ceramic interface.

\section{DISCUSSION}

Conventional mapping (Figure 2), utilizing the spectrum image data set, indicated $\mathrm{Ti}$ segregation to the metal/ceramic interface and segregation of $\mathrm{Fe}, \mathrm{Co}, \mathrm{Ni}$, and $\mathrm{Ti}$ to an apparent intermetallic phase in pockets along the same interface. In microstructures containing many elements, both major and minor, with a potentially complex distribution, it is desirable to automate the procedure for identifying not just the elements present but the phases and their distribution. This requires MSA of the entire spectrum image.

The MSA indicated that there were five distinct information-bearing components (i.e., above the noise level) which describe the spectrum image. Each component of information consists of a component image, which is the amplitude or relative weighting of the associated component spectrum. The original spectrum from a given pixel can be reconstructed by summing the products of the individual component-image pixel intensities and the respective component spectra. Therefore, instead of thousands of spectra, five spectra and five images describe all of the information resolved above the noise level. Furthermore, no assumptions have been made as to the presence or absence of any of the phases identified or any elements associated with those phases. Since the particular form of MSA applied here is variance based, the resultant components of information contain the maximum variance in as few components as possible. Therefore, it is unavoidable to obtain component spectra containing both positive and negative peaks. The physical significance of this is that signals of opposite polarity in a given component spectrum are anti-correlated in the microstructure. This can most clearly be seen in Figure 3 which is the component spectrum and image from the $\mathrm{Ag}$ and $\mathrm{Cu}: \mathrm{Cu}$ is positive in the component spectrum and correspondingly light in the component image; conversely, $\mathrm{Ag}$ is negative in the component spectrum and dark in the component image. Little contrast is observed in the other phases.

Figures $4 \mathrm{a}$ and $\mathrm{b}$ are the component image and spectrum from a (Ti, $\mathrm{Fe}, \mathrm{Ni}, \mathrm{Co})$ intermetallic phase found at the metal/ceramic interface. The light pockets in Fig $4 \mathrm{a}$ are a (Ti, Fe, Ni, Co) intermetallic phase. The positive peaks in the component spectrum from this phase (Fig. $4 \mathrm{~b}$ ) correspond with the light regions of the component image. Figures $4 \mathrm{c}$ and $\mathrm{d}$ are the component image and spectrum corresponding to interfacial segregation of $\mathrm{Ti}$. Again the light band at the metal/ceramic interface corresponds to the positive peaks in the component spectrum. Figure 5 is the sum of $25 \mathrm{raw}$ spectra from the metal/ceramic interface. Even though only those spectra with the highest Ti signal were summed to form the spectrum in Figure 5, several other elements are found together with the Ti. It should be noted that there were no raw spectra from that interface showing only $\mathrm{Ti}$. This is due to x-ray generation from the adjacent phases. In contrast, the MSA results of Fig. $4 \mathrm{~d}$ indicate that the $\mathrm{Ti}$ at the interface is essentially by itself. In other words, the Ti signal from the interface varies independently from the elements with which it is spectrally overlapped in the raw data. Although both the intermetallic identified in Fig. $4 \mathrm{a}$ and the interface phase identified in Fig. 4c both contain Ti (as shown in Fig. 2, the Ti map), MSA has determined them to be two different phases. This solution was arrived at with no operator intervention. Maps of $\mathrm{Fe}, \mathrm{Co}$ and $\mathrm{Ni}$ yielded essentially the same result but the power of MSA over conventional analyses is that no assumptions were made as to the presence of certain elements and thus the potential for missing important information is greatly reduced. 


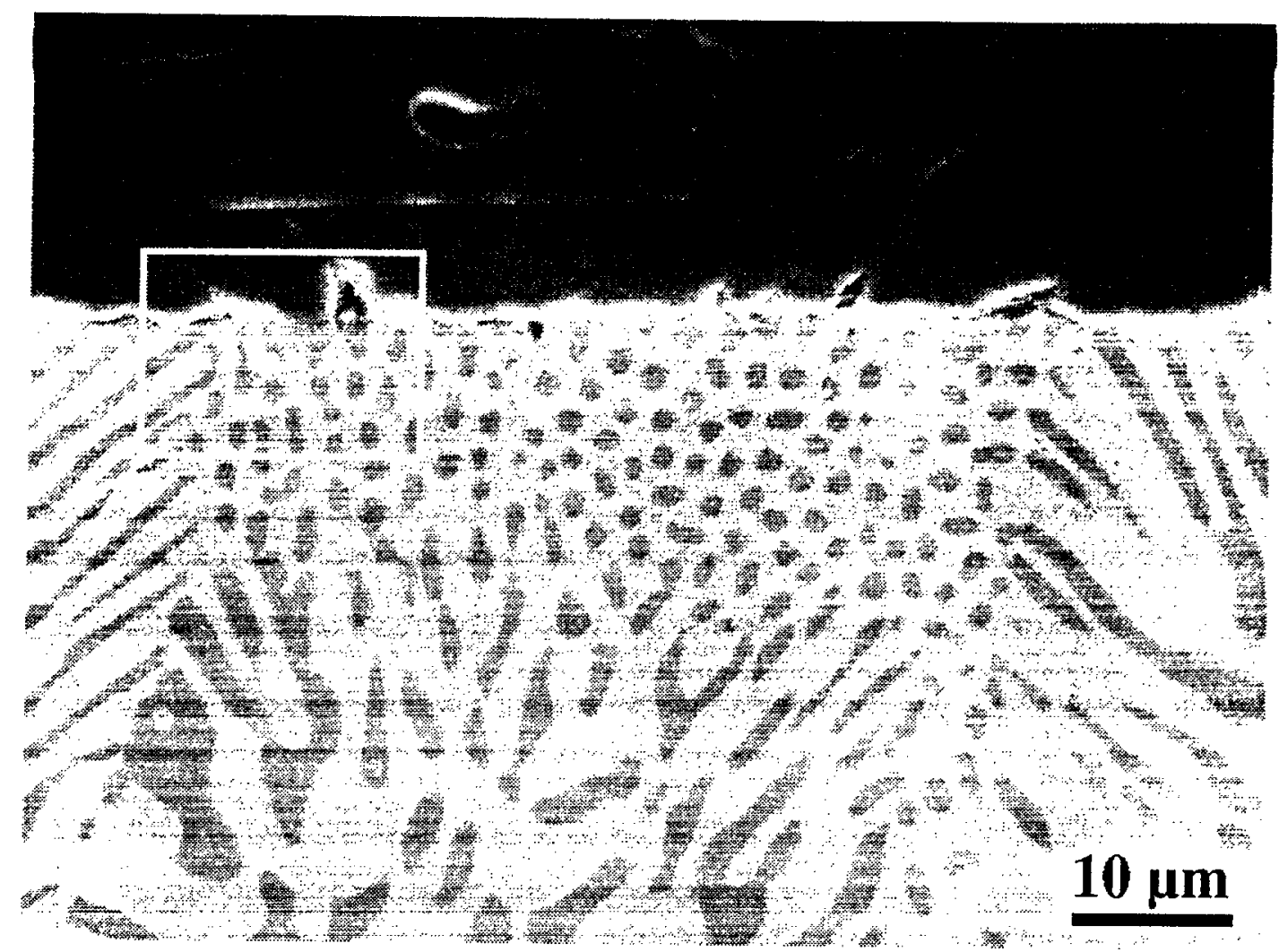

Figure 1. SEM secondary electron image of the analyzed region of the specimen.
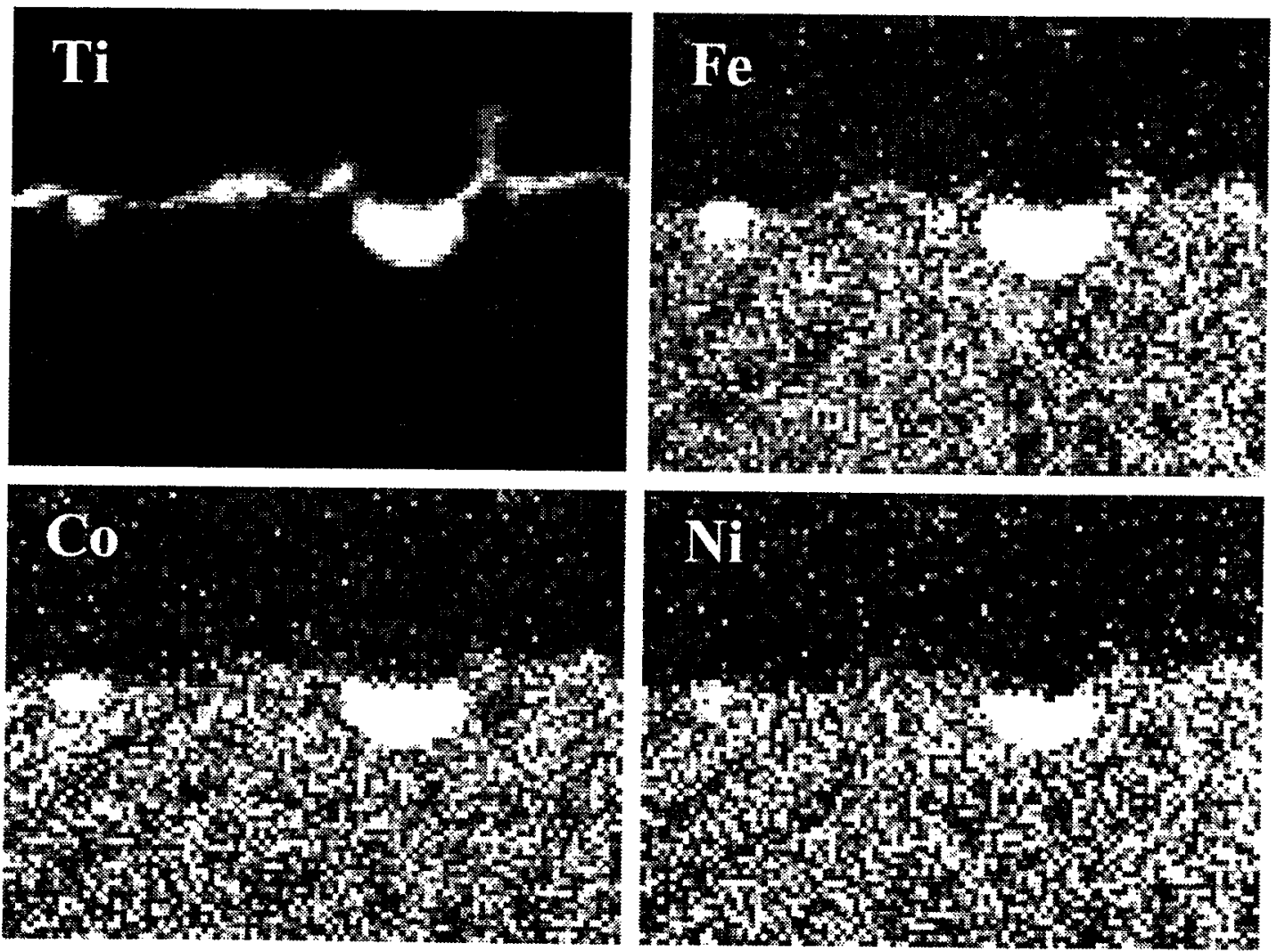

Figure 2. Conventional $\mathrm{x}$-ray maps constructed from the spectrum image data set. 

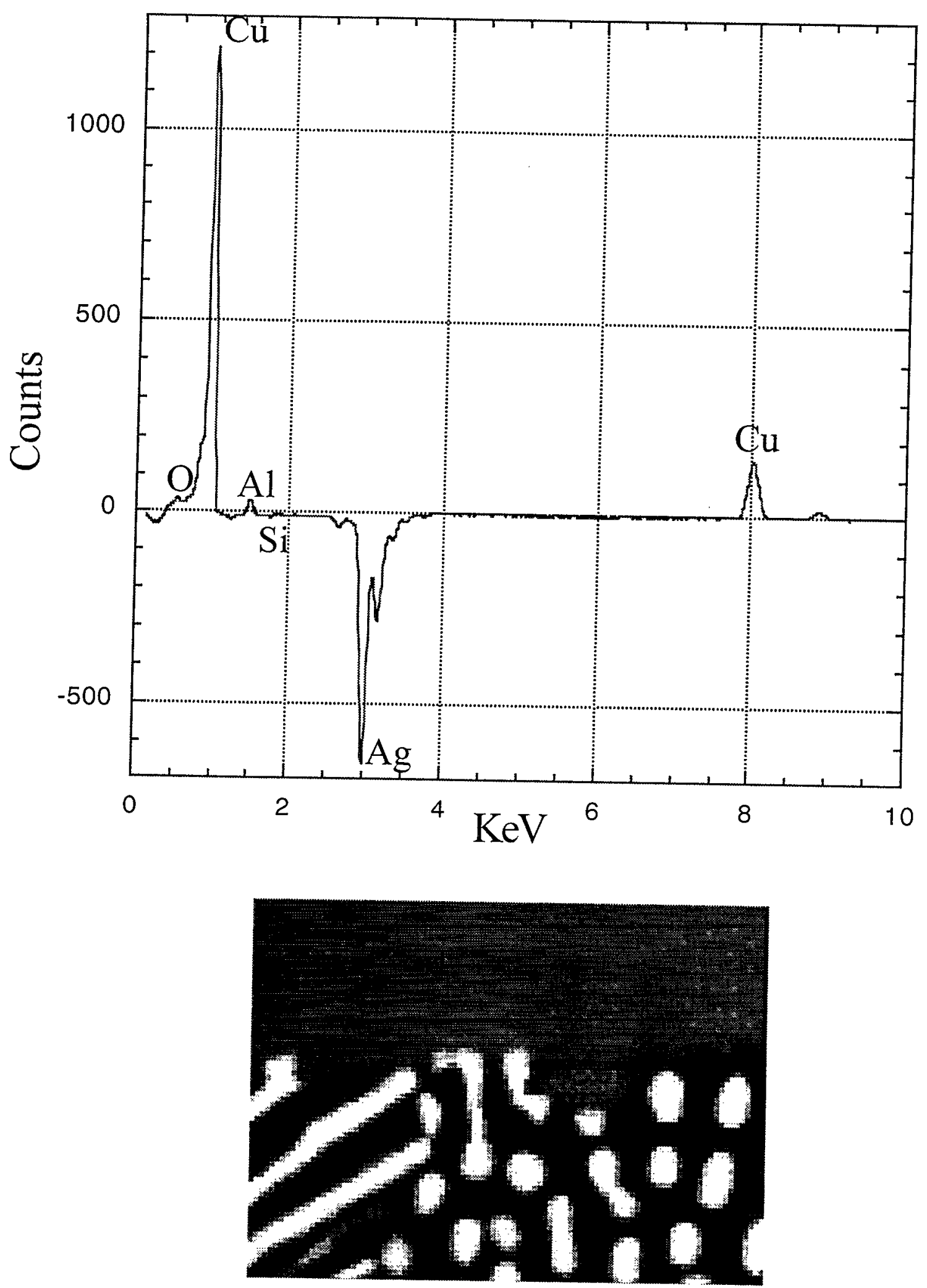

Figure 3. Component spectrum and image describing contrast in the $\mathrm{Cu} / \mathrm{Ag}$ eutectic. 


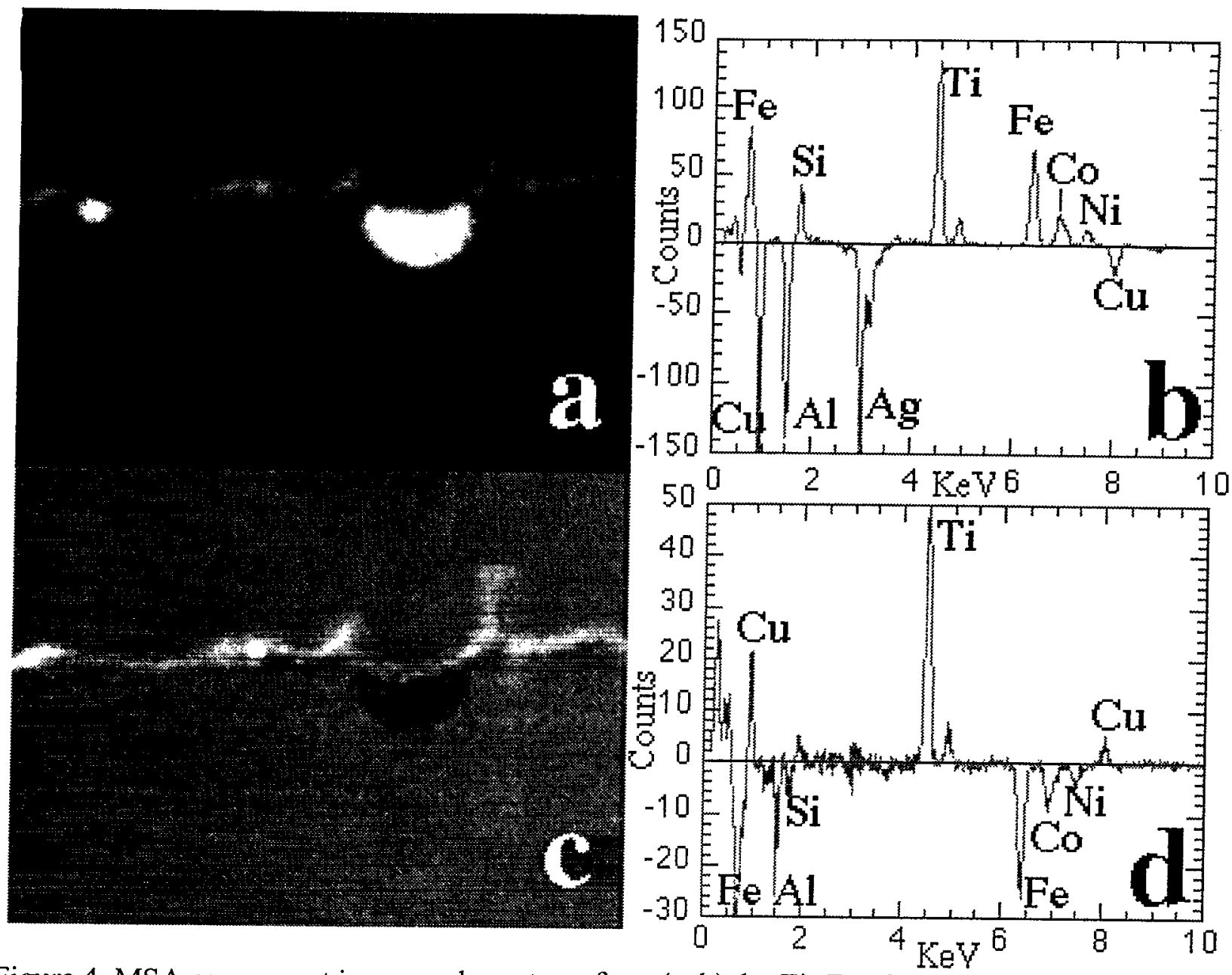

Figure 4. MSA component image and spectrum from $(\mathrm{a}, \mathrm{b})$ the $\mathrm{Ti}, \mathrm{Fe}, \mathrm{Co}, \mathrm{Ni}$ intermetallic phase and $(c, d)$ interfacial segregation of Ti.

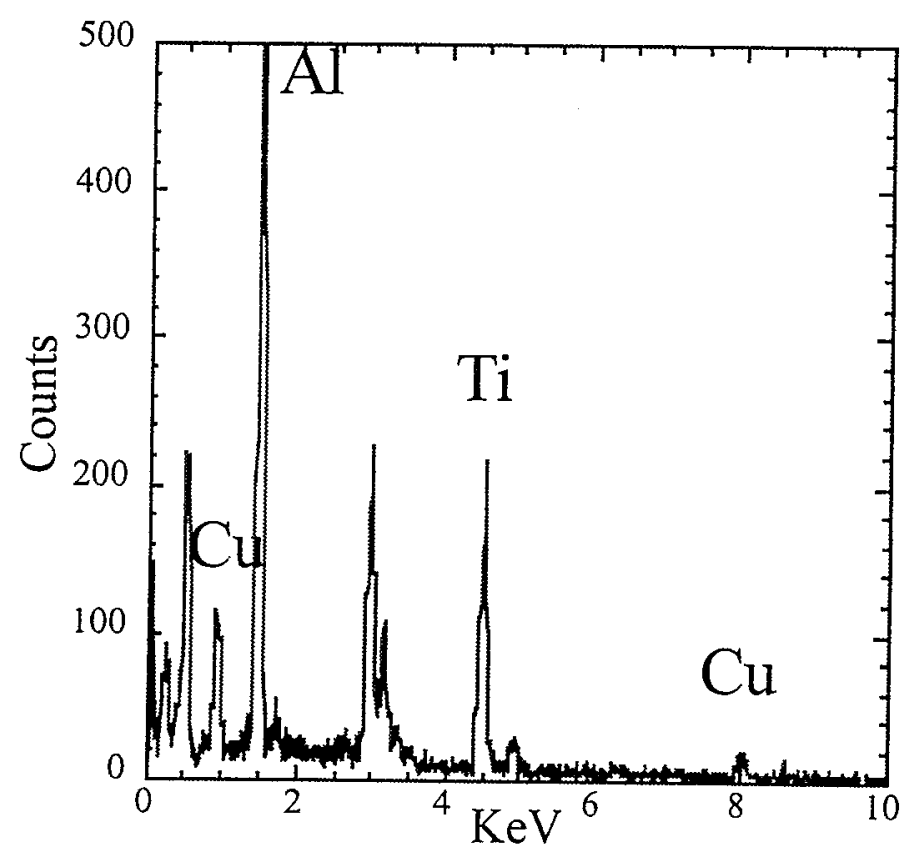

Figure 5. Sum of 25 raw spectra from the metal/ceramic interface. 


\section{CONCLUSIONS}

MSA has been successfully applied to the characterization of a metal ceramic braze. The chemistry and distribution of six phases were identified in the microstructure without any operator intervention. Future work will focus on obtaining pure component spectra that can then be quantified.

\section{ACKNOWLEDGMENTS}

Sandia is a multi-program laboratory operated by Sandia Corporation, a Lockheed Martin Company, for the United States Department of Energy (DOE) under contract DE-AC0494AL85000. Research at the ORNL SHaRE User Facility was sponsored by the Division of Materials Sciences, U.S. DOE, under contract DE-AC05-96OR22464 with Lockheed Martin Energy Research Corp., and through the SHaRE Program under contract DE-AC05-76OR00033 with Oak Ridge Associated Universities.

\section{REFERENCES}

1. D. E. Newbury and D. S. Bright, Microscopy and Microanalysis 5 (1999) 333.

2. P. Trebbia and N. Bonnet, Ultramicroscopy 34 (1990) 165.

3. I. M. Anderson and J. Bentley, Proc. Microscopy \& Microanalysis 1997, 931.

4. I. M. Anderson and J. Bentley, Mater. Res. Soc. Symp. Proc. 458 (1997) 81.

5. $\quad$ I. M. Anderson, Proc. 14 $4^{\text {th }}$ ICEM: Electron Microscopy 19981 (1998) 357. 